\title{
Regulatory, Policy, and Operational Considerations for Outcomes-Based Risk-Sharing Agreements in the U.S. Market: Opportunities for Reform
}

\author{
Clifford Goodman, PhD; Christel Villarivera, MS; Karl Gregor, PharmD, MS; and Julie van Bavel, MPH
}

\begin{abstract}
BACKGROUND: Although interest in outcomes-based risk-sharing agreements (OBRSAs) and other value-based contracts (VBCs) continues to grow, the number of VBCs in the United States is still limited. A better understanding of the evolving and fluid context of policies, regulations, and operational factors affecting their uptake in the United States is needed in order to lower or obviate barriers and advance OBRSAs.
\end{abstract}

OBJECTIVES: To (a) identify and recognize priorities among policies, regulations, and other factors that are most likely to influence the feasibility, design, and execution of OBRSAs and (b) suggest opportunities for reform and other modifications that may advance OBRSAs in the United States.

METHODS: Across 18 months during 2017-2018, we reviewed health policy literature, examined stakeholder group communications, and conducted semistructured interviews with representatives of 12 diverse stakeholder organizations. Across these, and incorporating real-time contextual changes, we identified priorities for enabling and improving OBRSAs.

RESULTS: Regulatory and policy priorities most often cited by manufacturers were Medicaid best price rule, Medicare Part B average sales pricing, FDA restrictions on communications, and the Anti-Kickback Statute. While recognizing these, health plans were more concerned about operational barriers, particularly associated with data collection and analysis, selection of outcomes that are feasible to assess, bandwidth for managing OBRSAs, and implementation costs relative to return on investment. Most recognized limitations on access to personal health information, target population turnover, and insufficient information sharing of OBRSA experiences. Noteworthy were asymmetries of administrative burden and cost management: individual manufacturers may pursue 0BRSAs for 1 or a few products per year, while health plans are approached by multiple manufacturers about OBRSAs for their respective products; manufacturers focus on drugs, while health plans must manage broader costs of care.

CONCLUSIONS: While all stakeholders express interest in OBRSAs, health plans tend to consider them as a narrower priority than manufacturers. Solving operational barriers, in addition to addressing policy and regulatory barriers, is essential for aligning efforts to advance OBRSAs. Doing so depends on collaboration to improve decisions about when and how to pursue OBRSAs, with attention to data management, modeling and piloting OBRSAs, and information sharing. These findings pertain to companies operating in the United States and some likely extend to certain valuebased arrangements in other countries.

J Manag Care Spec Pharm. 2019;25(11):1174-81

Copyright $\odot 2019$, Academy of Managed Care Pharmacy. All rights reserved.

\section{What is already known about this subject}

Value-based contracts (VBCs), including outcomes-based risksharing agreements (OBRSAs), have emerged as value-driven alternative payment models for pharmaceuticals, particularly for certain high-priced, innovative drugs.

Although interest in OBRSAs and other VBCs is increasing, their use is still limited in the United States because of commonly cited policy, regulatory, and operational barriers and other barriers.

Information on OBRSAs and other VBCs that is available in the public domain underestimates the actual level of VBC activity, limiting the knowledge base on the potential effect of VBCs.

\section{What this study adds}

Although there is generally convergent recognition of barriers to VBCs, various stakeholders, including potential partners, differ in their perceptions of the importance and implications of these barriers.

Toward developing VBC guiding principles and best practices, stakeholders desire more information in the public domain about real-world experiences with these models

An increasingly supportive environment for OBRSAs depends on monitoring of and response to existing and proposed policies, regulations, and other factors. $\mathrm{s}$ the U.S. health care system continues to shift from an emphasis on volume to value of care, payment mechanisms are adapting accordingly. Of the projected $\$ 3.6$ trillion spent on U.S. health care in 2018 , nearly $10 \%$, or $\$ 344.5$ billion, was spent on prescription drugs. ${ }^{1}$ Value-based contracting offers alternative payment models for managing risk in resource allocation for drugs, particularly for certain high-priced, innovative drugs, incentivizing clinically appropriate access in order to achieve improved outcomes in indicated patients.

Value-based contracts (VBCs) are typically risk-sharing agreements between manufacturers and payers that link coverage and reimbursement to a drug's performance based on 1 or more parameters of value (e.g., patient outcomes, efficiency, and financial performance). Outcomes-based risksharing agreements (OBRSAs), also known as outcomes-based 


\section{TABLE 1 Literature Search}

Searched PubMed/MEDLINE and gray literature for current information and new developments on policies, regulations, and trends posing potential challenges or opportunities for OBRSAs and other VBCs; identified operational barriers and resource concerns that may affect their design and uptake

Search conducted in March and April 2017 with no search date limits; reran searches at least once each quarter through June 2018

PubMed/MEDLINE: Medical Subject Heading (MeSH) terms (e.g., Drug Costs [mh], Contract Services/economics [mh], Economics, Pharmaceutical [mh] Prescription Drugs/economics [mh]) and key text terms (e.g., outcomes-based contract*, performance-based contract*, value-based contract*, risk-sharing agreement ${ }^{*}$ ) Gray literature sources: industry reports, pharma/bio company press releases announcing OBRSAs/VBCs, health care policy and industry newsletters and blogs, news publications, government websites and publications (e.g., FDA, CMS, OIG), and professional association websites

CMS = Centers for Medicare \& Medicaid Services; FDA =U.S. Food and Drug Administration; OBRSA = outcomes-based risk-sharing agreement; $O I G=O$ ffice of the Inspector General, Department of Health and Human Services; VBC = valuebased contract.

contracts, are a type of VBC in which a manufacturer and a payer link payment to real-world performance of patient outcomes over a specified time frame.

OBRSAs and other VBCs are on the rise as interest in and experience with these models grows. According to PhRMA, 62 VBCs had been executed and publicly announced in the United States from 2009 through mid-2019, ${ }^{2}$ while other recent surveys of industry, health plan, and pharmacy benefit manager (PBM) representatives indicate that the actual number of implemented VBCs is much higher. ${ }^{3,4}$

Nevertheless, interest in VBCs is accompanied by scrutiny of their potential roles, utility, and challenges. Considering, planning, and implementing OBRSAs are subject to a diverse context of policy, regulatory, and other operational factors.

This analysis was a component of the Learning Laboratory for Advancing Value-Based Healthcare, a multiyear collaboration between Merck Sharp \& Dohme (MSD), a subsidiary of Merck, and Optum. Its intent was to develop and test predictive outcomes-based and financial models to better understand the variables, populations, and clinical characteristics that predict clinical and financial outcomes; explore new models and methods from different stakeholder perspectives; and develop OBRSA contracting archetypes.

The purpose of this analysis was to identify and recognize priorities among policies, regulations, and other factors most likely to influence the feasibility, design, and execution of OBRSAs and to suggest opportunities for reform and other modifications that may advance OBRSAs in the United States.

\section{Methods}

\section{Literature Review}

We searched the peer-reviewed literature to identify relevant research addressing policy, regulatory, and other factors.

\section{TABLE 2 Guiding Questions}

1. From your perspective, what do you feel are the most important policy/ regulatory barriers to OBRSAs and other VBCs? Can any be addressed without significant changes to these policies/regulations?

2. What are the most important operational barriers to OBRSAs and other VBCs? What is needed to address these barriers?

3. What types (range and most common examples) of OBRSAs and other VBCs are being implemented?

4. Are certain types of OBRSAs and other VBCs easier to implement? Are there proposed policies/regulations that you believe will support VBCs if passed?

5. OBRSAs and other VBCs appear to be a focus of many recent conferences and meetings. In your opinion, is there more momentum now for OBRSAs and other VBCs in the current environment?

6. What would innovation look like? What learnings could help advance the design and implementation of OBRSAs and other VBCs?

Note: The order and relevance of these questions varied across the interviews. Additional relevant questions arose depending on interviewee perspectives and interests pertaining to VBCs.

$O B R S A=$ outcomes-based risk-sharing agreement; $V B C=$ value-based contract

Searches were conducted in March and April 2017 with no search date limits. We reran the searches at least quarterly through June 2018 to identify new, potentially relevant articles (Table 1).

We also probed diverse gray literature sources to identify policies, regulations, and trends posing potential challenges or opportunities for OBRSAs.

\section{Stakeholder Interviews}

We conducted telephone interviews with 12 prominent stakeholders and leading experts in VBC and related fields who provided additional information on the evolving context for these arrangements. Interviewees were all senior-level representatives of their respective private or public sector organizations (including $\mathrm{CEOs,} \mathrm{CMOs}$, vice presidents, directors, and senior researchers) and were selected to provide a range of perspectives, including payers (private sector and state Medicaid), PBMs, providers, manufacturers, and health policy researchers, as well as experts in value-based payment. Interviews were scheduled for at least 30 minutes, with some extending to 60 minutes, and in some cases, interviewees included additional people from their organizations in the interviews. Interviewees were asked for permission to have an MSD staff person on the call, noting that MSD would not join the call if the interviewee thought that would affect one's remarks. We informed interviewees who chose not to have MSD on the call that no findings would be attributed to specific interviewees. Table 2 lists questions we developed in consultation with MSD to guide the interviews, although the interviews were not limited to these questions. 


\begin{tabular}{l|l}
\hline \multicolumn{1}{c}{ TABLE 3 } & \multicolumn{1}{c}{$\begin{array}{c}\text { Most Often Cited Policy } \\
\text { and Regulatory Factors }\end{array}$} \\
\hline Policy/Regulation & \multicolumn{1}{c}{ Common Concerns } \\
\hline - Medicaid best price rule & $\begin{array}{l}\text { - Triggering of rules that would } \\
\text { set new pricing for drugs under } \\
\text { - 340B Drug Discount Program }\end{array}$ \\
- Medicare Part B ASP & $\begin{array}{l}\text { - Uncertainty about applicability to } \\
\text { VBCs and concerns about need for } \\
\text { explicit safe harbors or waivers }\end{array}$ \\
\hline - Antikickback statute & $\begin{array}{l}\text { Timing of discussions, discussions } \\
\text { of off-label uses }\end{array}$ \\
\hline $\begin{array}{l}\text { tions from manufacturers to health } \\
\text { plans, others }\end{array}$ & $\begin{array}{l}\text { ASP=average sales price; FDA=U.S. Food and Drug Administration; } \\
\text { VBC=value-based contract. }\end{array}$
\end{tabular}

\section{Results}

\section{Policy and Regulatory Factors}

We identified policies and regulations affecting the use of OBRSAs that were consistently cited in the literature and via interviews; the most commonly cited are listed in Table 3.

Medicaid Best Price Rule, 340B Drug Discount Program, and Medicare Part B Average Sales Price. Under the Medicaid best price rule, drug manufacturers must offer state Medicaid programs the best price given to any other purchaser, with a few exceptions. For purposes of VBCs, manufacturers are wary of this rule because prices, or net prices, of drugs offered to a health plan in a VBC_-even including a greatly reduced or zero net price for a drug found to be ineffective in individual patients-could be interpreted as triggering the Medicaid bestprice rule and, thereby, set a new (i.e., lower) best price of a drug, even though the Medicaid program itself would not be subject to the VBC requirements.

Manufacturers express similar concerns regarding the federal 340B Drug Discount Program and the Medicare Part B average sales price (ASP). A low net price in a VBC could trigger compulsory price reductions in the 340B Program, forcing ceiling prices paid by covered entities further downward. Under Medicare Part B, for medical benefit drugs, manufacturers must report the ASP to the Centers for Medicare \& Medicaid Services (CMS) on a quarterly basis. ${ }^{5}$ Manufacturers are concerned that any substantial rebates that VBCs offer to health plans would reduce ASP, which would reduce Medicare Part B reimbursement rates for their products.

Anti-Kickback Statute. Manufacturers are concerned that the federal Anti-Kickback Statute (AKS) could be interpreted in ways that would limit OBRSAs and other VBCs. VBC arrangements could be interpreted as seeking to induce provider institutions and formularies to narrow their offerings to particular manufacturers' drugs. A common concern is uncertainty about potential infringement on AKS in which a

\section{TABLE 4 Most Commonly Cited} Operational Barriers

\begin{tabular}{|c|c|}
\hline Data Concerns & Resource Concerns \\
\hline $\begin{array}{l}\text { - Selection of outcomes that are } \\
\text { feasible to assess } \\
\text { - Relevance/validity of clinical trial } \\
\text { data for real-world OBRSAs } \\
\text { - Data infrastructure of sufficient } \\
\text { capacity/efficiency/ timeliness } \\
\text { - Time horizon/duration of OBRSAs } \\
\text { relative to care episodes }\end{array}$ & $\begin{array}{l}\text { - Insufficient health plan/payer } \\
\text { "bandwidth" (expertise/FTEs) to } \\
\text { manage an OBRSA } \\
\text { - Managing multiple VBCs } \\
\text { simultaneously } \\
\text { - Potential for acceptable return on } \\
\text { investment of implementing an } \\
\text { OBRSA } \\
\text { - Interactive effects of drug portfolio } \\
\text { deals } \\
\text { - Dealing with multiple VBCs }\end{array}$ \\
\hline
\end{tabular}

FTE = full-time equivalent; OBRSA = outcomes-based risk-sharing agreement; $V B C=$ value-based contract

manufacturer agrees to provide additional services under a VBC, such as medication adherence support (i.e., which could constitute something of value under AKS). Other concerns include payment for diagnostic tests associated with a drug and rebates for poor outcomes as designated under an OBRSA.

FDA Restrictions on Manufacturer Communications. Manufacturer concerns about U.S. Food and Drug Administration (FDA) restrictions on manufacturer communications to health plans, PBMs, and others have been identified as barriers to entering into OBRSAs and other VBCs. These barriers have been cited by some payers as well. ${ }^{6}$ To inform premium-setting and related benefits considerations, health plans would prefer to have information about anticipated indications and outcomes 12-18 months before drug approval. These rules have limited manufacturers to discussing matters of FDA-approved labeling only, which may involve intermediate endpoints in clinical trials instead of real-word, patientcentered outcomes that may be more relevant for beneficiaries. As such, health plans may not have the information about outcomes that would pertain to OBRSAs at the time of launch, diminishing their ability to exert value-based leverage for newly approved drugs. Manufacturers have also been precluded from proactively communicating economic evidence not addressed in FDA-approved labels. These regulatory conditions were significantly modified by guidance documents released by the FDA in June 2018, as described in the Discussion section.

\section{Operational Barriers}

Our literature review and interviewees identified substantial operational barriers to OBRSAs and other VBCs. Overcoming these typically does not require regulatory change; there may be greater potential to diminish these barriers through targeted efforts. Table 4 lists these barriers, the most common of which comprise data and resource concerns. 
Data Concerns. Among data management concerns are outcomes designation and data availability. Health plans prefer using clinically relevant outcomes (i.e., primary endpoints that can be objectively measured and readily assessed). Ideally, OBRSAs would use metrics that can be captured in reliable, and preferably routinely available, data sources and are attributable to the drug intervention. Although some biomarkers are acceptable as reliable surrogates for hard outcomes, the applicable laboratory or radiological data regarded as outcome surrogates are often underreported or otherwise not readily available.

Available data infrastructures may lack sufficient capacity, efficiency, and timeliness to support OBRSAs. Data collection and sharing barriers exist between the medical benefit and the pharmacy benefit silos of many health plans. While insurance claims provide documentation of diagnoses, procedures, prescriptions, tests, and billing information, they were not intended for tracking health outcomes and often are missing data, thereby limiting their utility-at least when not complemented by other data sources-for OBRSAs. Although many proposed OBRSAs would rely on electronic health records (EHRs) to provide outcome and biomarker data, some health plans do not have EHRs (or sufficiently integrated ones), and manufacturers do not have routine EHR access. Relevance of clinical trial data for real-world settings raises concerns; evidence from clinical trials used to bring a drug to market may be insufficient, unreliable, or impractical for an OBRSA. As oversight and patient management in clinical trials are likely to be greater than in community settings, patient adherence, for example, is likely to be lower in real-world settings. Patient selection criteria for a premarket clinical trial may be impractical for the real world, where patient populations tend to be more heterogeneous, have more comorbidities, and be more subject to behavioral and environmental factors that may influence outcomes.

The time span of OBRSAs may not align with therapeutic effect on outcomes. For some diseases, it will take longer to detect clinical effect of a drug than a practical contract vehicle might allow. As most patients enroll in health plans on an annual basis, the inevitable "churn" may make it difficult to link patient population effects with enrollment periods. Further, as new drugs enter the market, the number of patients who are prescribed a drug may change markedly and unexpectedly. As such, OBRSAs typically need to be short term, as payers generally do not want their options limited for periods extending beyond their typical decision-making horizons.

Resource Concerns. Among resource concerns, particularly among health plans, is insufficient bandwidth (i.e., expertise and staff resources) to manage OBRSAs, especially for smaller health plans. Plans may regard OBRSA implementation as another layer of administrative burden and costs. Payers seek a strong return on investment (ROI) rationale and feasible pathways for entering into OBRSAs.

Portfolio deals that involve multiple drugs from 1 manufacturer can encourage or enable suboptimal drug selection. For example, although 1 drug offered in an OBRSA might outperform another for a given indication, the outperformed drug might already be included in a contract with a PBM for other indications. In this case, the health plan is unlikely to change to the more cost-effective product for that indication, given the ties to rebates for the other indications.

Dealing with potentially multiple VBCs simultaneously poses resource concerns. Plans may be approached to consider VBCs for newly launched drugs from multiple manufacturers. Even for 1 disease area, health plans have to work across a spectrum of health care benefits and services-not just the drugs — with their attendant operational demands.

\section{Additional Interview Findings}

Although our interview findings largely mirrored those from the literature, they revealed certain additional concerns and contrasting perspectives. These differences can pose challenges to aligning stakeholder efforts to support OBRSAs and other VBCs.

Differing Stakeholder Perspectives and Priorities. Manufacturer interviewees expressed greater concern about policy and regulatory barriers than other stakeholders. For example, while manufacturers are concerned about FDA rules pertaining to communications with health plans about a drug before approval or about off-label use, interviewees from health plans indicated that they are able to at least partially circumvent this issue. To inform their expectations about the value of a drug, plans can gather intelligence from alternative sources (e.g., investors, PBMs doing pipeline tracking, and health technology assessment bodies). As such, despite limitations on communications by manufacturers, plans have latitude to enter contracting discussions better prepared. Although manufacturers cannot market unapproved indications of a drug, health plans can, apart from a VBC, widen access to a drug by covering a clinician-prescribed off-label use when they judge that the drug is medically appropriate (though not experimental or investigational) for a particular patient.

Health plans and PBMs regard the major barriers to VBCs to be mainly operational, particularly regarding data and resource needs. Addressing these concerns requires improved data infrastructure, greater information sharing (as appropriate) from manufacturers before drug approval, and additional resources to manage multiple VBCs. These differing perspectives reflect asymmetry between how manufacturers and plans pursue VBCs. To a health plan, the prospect of a VBC for a given drug may represent a one-time arrangement among a broader array of costly clinical services and other therapies, 


\section{TABLE 5 Actions to Achieve Regulatory and Policy Reform}

Policy/Regulatory Factor

Medicaid best price rule

a

in

Anti-Kickback Statute

Recommended Steps and Recent Developments

Advocate for CMS to provide safe harbor, carve-out, waiver, or other accommodation so that VBCs are exempt from Medicaid best price rule.

Although CMS withdrew its OBRSA with Novartis for Kymriah, ${ }^{a}$ CMS still acknowledges the need to address VBCs and approved a waiver for Oklahoma Medicaid in June 2018 that allowed it to be the first state Medicaid program to sign VBCs for prescription drugs. ${ }^{\mathrm{b}}$ The State Medicaid Alternative Reimbursement and Purchasing Test for High-Cost Drugs helped Oklahoma apply for the state plan amendment that enabled it to enter into VBCs under its Medicaid Drug Rebate Program.

In November 2018, CMS announced its approval of Michigan Medicaid's state plan amendment that authorizes the state to enter into outcomes-based contract arrangements with drug manufacturers through supplemental rebate agreements. ${ }^{c}$

In February 2019, CMS announced its approval of Colorado Medicaid's state plan amendment that authorizes the state to enter into value-based contract arrangements with drug manufacturers through supplemental rebate agreements. ${ }^{\mathrm{d}}$

Advocate for the OIG to issue guidance on safe harbors and waivers to the AKS to enable certain aspects of VBCs.

On January 31, 2019, the OIG announced a proposed rule under AKS, "Removal of Safe Harbor Protection for Rebates Involving Prescription Pharmaceuticals and Creation of New Safe Harbor Protection for Certain Point-of-Sale Reductions in Price on Prescription Pharmaceuticals and Certain Pharmacy Benefit Manager Service Fees." Stating that the proposed rule is not intended to affect value-based arrangements, the OIG requested comments from stakeholders on how the proposed rule may affect such arrangements.

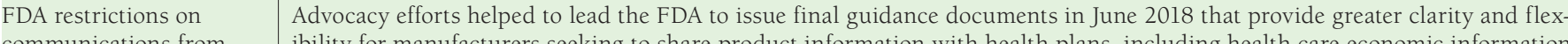
communications from ibility for manufacturers seeking to share product information with health plans, including health care economic information, in manufacturers to payers discussions of OBRSAs and other VBCs.

a Karlin-Smith S, Pittman D. CMS quit test of pricey cancer treatment amid concerns over industry role. Politico. September 9, 2018. Available at: https://www.politico. com/story/2018/07/09/cms-quit-test-of-pricey-cancer-treatment-amid-concerns-over-industry-role-674086. Accessed August 15, 2019.

${ }^{b}$ Reck J. Oklahoma signs the nation's first state Medicaid value-based contracts for Rx drugs. National Academy for State Health Policy. September 25, 2018. Available at: https://nashp.org/oklahoma-signs-first-medicaid-value-based-contracts-for-rx-drugs/. Accessed August 15, 2019.

${ }^{c}$ Centers for Medicare \& Medicaid Services. Michigan State Plan Amendment. Approval letter. November 14, 2018. Available at: https://www.medicaid.gov/State-resourcecenter/Medicaid-State-Plan-Amendments/Downloads/MI/MI-18-0009.pdf. Accessed August 15, 2019.

${ }^{d}$ Centers for Medicare \& Medicaid Services. Colorado's State Plan Amendment. Approval letter. February 25, 2019. Available at: https://www.medicaid.gov/State-resourcecenter/Medicaid-State-Plan-Amendments/Downloads/CO/CO-18-0044.pdf. Accessed August 15, 2019.

AKS =Anti-Kickback Statute; CMS =Centers for Medicare \& Medicaid Services; FDA=U.S. Food and Drug Administration; OBRSA=outcomes-based risk-sharing agreement; OIG =Office of the Inspector General, Department of Health and Human Services; VBC=value-based contract.

whereas a manufacturer is likely focused on 1 or more VBCs for its product.

While information on state activities in the literature is limited, stakeholder interviews revealed that state Medicaid programs are interested in VBCs but have their own operational concerns, including implementing OBRSAs within the constraints of state budget cycles. States' annual budget planning and spending cycles may not align with availability of information to develop OBRSAs or time spans for achieving target outcomes. Similarly to commercial plans, Medicaid programs are also concerned about their ability to focus limited staff and resources on VBCs given other pressing priorities. Medicaid programs are also wary of becoming locked into VBCs that would preclude adjusting their benefits or formularies in order to provide access to new drugs. CMS has approved plans by at least 3 state Medicaid programs to pursue VBCs under their rebate programs, for example, based on net costs, adherence, and outcomes (Table 5).

Stakeholder Need for More Information. The interviews revealed the desire of stakeholders for more information in the public domain about real-world experiences with OBRSAs and other VBCs. Consistent with earlier reports, interviewees emphasized that what is in the public domain underestimates the actual level of $\mathrm{VBC}$ activity, limiting the knowledge base and willingness to consider such agreements. ${ }^{7.8}$ Recent examinations of public announcements and surveys of manufacturers and payers reflecting expansion in number of VBCs also continue to reflect this gap.,10

More publications and other information sharing about these experiences and lessons learned could support development of VBC guiding principles and best practices. A limitation to such information sharing is that health plans and manufacturers must make what can be costly investments to engage in VBCs and may be reluctant to share insights of competitive value. Companies own experiences with VBCs will influence decisions about whether and how to pursue further VBCs, and PBMs and other parties that work with multiple manufacturers and payers will apply their knowledge and practices more broadly.

\section{Discussion}

\section{Addressing Priority Policy and Regulatory Barriers}

Medicaid Best Price Rule. While various forms of VBCs are implemented, stakeholders still perceive barriers to realizing their potential. They have called for waivers or carve-outs and related guidance for VBCs to avoid triggering the Medicaid best 
price rule. In a July 2016 program notice, CMS encouraged manufacturers to seek CMS guidance on whether and how their VBCs might affect the best price rule. One interpretation of the notice has been that manufacturers are encouraged to experiment with VBCs in Medicaid first. Some have called for a waiver or other mechanism to protect Medicare Part B ASPs, as well as guidance or reforms pertaining to the 340B Program.

Anti-Kickback Statute. Manufacturers have approached the Office of the Inspector General (OIG) to obtain safe harbors or waivers under this statute to enable piloting or implementing VBCs. Safe harbor proposals for VBCs have included provisions for activities such as patient adherence programs and providing analytical support to providers. Since 2015, safe harbor requests focused on VBCs have increased. Still, these are one-time fixes. ${ }^{11}$

In 2017, the OIG posted the same response to each safe harbor or waiver request it received, stating that it was not adopting the suggestion and that questions about applying the AKS to VBCs should be addressed on a case-by-case basis. In September 2017, the OIG further clarified the scope of its AKS warranty safe harbor, stating that it recognizes that it can provide protection for a warranty for many reasons, including "failure to meet quality standards or failing to achieve patient targets at the time of sale." This broadening of the OIG's guidance may help to facilitate VBCs. ${ }^{12,13}$ Efforts continue to have the OIG carve out VBC-specific protections. ${ }^{14}$

Other concerns raised by the Trump administration could work against VBCs. In May 2018, administration officials questioned whether drug rebates provided by manufacturers to PBMs and other payers should retain safe harbor status under the AKS, noting that the AKS makes it illegal to pay an incentive for drugs or services that are covered under federal health care programs. These views have arisen as the administration considers options to manage high drug prices and expresses concerns that rebates incentivize setting high initial prices for drugs and discourage competition.

On January 31, 2019, the OIG announced a proposed rule intended to lower prescription drug list prices and reduce patient out-of-pocket costs. ${ }^{15}$ The safe harbor rule change would affect manufacturer rebates offered to Medicare Part D plans (including Medicare Advantage Prescription Drug plans), Medicaid managed care organizations, and their PBMs. Excluded from the rule change would be price discounts or rebates required by law, such as state Medicaid program rebates or Medicaid best price rules. Although the proposed rule would not directly affect manufacturer discounts to commercial health plans, it could have indirect impacts in those markets.

The proposed rule states that the OIG "does not intend for this proposal to have any effect on existing protections for value-based arrangements between manufacturers and plan sponsors." However, it does not specify any exclusions that would protect value-based arrangements, which have included various rebates and other price concessions, as well as additional services (e.g., for medication adherence, analytic support, diagnostic tests) that could be interpreted as conveying value under AKS.

Concurrent with the OIG proposed rule, 2 senators introduced a draft bill that would provide a safe harbor for value-based payments. Among its provisions, the bill would exclude certain value-based arrangements from the AKS and exclude drugs purchased through such arrangements from Medicaid best price requirements and average manufacturer price determinations. ${ }^{16}$

FDA Restrictions on Manufacturer Communications. In June 2018, the FDA provided greater clarity and flexibility for manufacturers seeking to share product information in ways that could facilitate OBRSAs and other VBCs. The FDA released final guidance documents addressing manufacturer communications with payers and other entities. One guideline applies to communication of health care economic information to payers, including discussions between manufacturers and payers regarding risk-bearing and other $\mathrm{VBCs} .{ }^{17}$ It clarifies that the FDA does not regulate or have reporting requirements for such contracts and that the guidance is not intended to address terms of such contracts. The other guideline describes how manufacturers can convey "truthful and nonmisleading" information that is not contained in FDA labeling but that is consistent with that labeling. ${ }^{18}$

These FDA guidance documents should lower certain regulatory barriers to planning and implementing OBRSAs and other VBCs. They enable earlier and expanded discussions about outcomes, economic information, prospective patient utilization, and as-yet unapproved products and unapproved uses that are awaiting FDA approval. Manufacturers can share unapproved product and use information as long as such information clearly states: that the product or use is not approved, its anticipated timeline for potential FDA approval/clearance/ licensure, and results of clinical studies. The FDA indicated it will not take enforcement action for manufacturer communications to payers of information about an unapproved product or an unapproved use of an approved/cleared/licensed product when such information is "unbiased, factual, accurate, and nonmisleading." The FDA notes that such communications "can allow payors to provide coverage for these new products and new uses more quickly after FDA approval or clearance."

\section{Addressing Priority Operational Barriers}

Our payer interviewees indicated interest in overcoming data and resource-related barriers. A practical consideration for payers is simply establishing fundamental expertise and experience with OBRSAs, including standing up models or other analytical tools for gauging the ROI of OBRSAs.

Vendors and other third parties are showing interest in providing technologies to support data infrastructure and 
analytics to execute VBCs, including integrating disparate data sources and using cloud-based platforms for pharmacy and medical data repositories. These companies claim to offer trusted environments for health plan and manufacturer data.

Interviewees indicated that manufacturers that offer such value-added services as case management support, adverse event monitoring, adherence monitoring, and analytical support can diminish the burden and risks of entering into a VBC. Again though, these interviewees are wary that such add-ons could be interpreted as infringing on the AKS.

Practical examples of overcoming operational barriers are emerging into the public domain. Among these are instances of adapting data collection to particular drug indications, episodes of care, outcomes of interest, data availability, and analytical capacity. For example, an agreement between Oklahoma Medicaid and a manufacturer of a long-acting injectable antipsychotic provides for a 2-phase assessment, starting with population adherence, followed by clinical outcomes. ${ }^{19,20}$ Leveraging its analytical capabilities and access to large sets of medical and pharmacy data, a PBM owned by 18 Blue Cross and Blue Shield plans entered into a value-based agreement with a pharmaceutical company based on the ability of a diabetes drug to lower total cost of care compared with other diabetes drugs. ${ }^{21}$

\section{Limitations}

During and since our focused study comprising literature searches and interviews over the course of 18 months, the momentum for VBCs continues, albeit in a context of evolving policy proposals and political and legal uncertainties. Much VBC activity remains out of public view. We supplemented information from the literature with findings from interviews of a convenience sample of different stakeholders, including some currently engaged in OBRSAs. This study could not capture all perspectives, although this set of well-placed stakeholders provided firsthand insights and context that were not apparent in the literature.

\section{Conclusions}

The pipeline of innovative, yet often high-cost, drugs fuels demand for demonstrating value. However, value can be difficult to discern at key junctures of decision making. In many instances, the lack of real-world effectiveness and safety data around the time of market approval poses uncertainty and risks to payers and other stakeholders. In these circumstances, entering into VBCs, and OBRSAs in particular, offers risk mitigation that should inform and benefit patients as well as manufacturers, payers, and providers. Nevertheless, certain prevailing and proposed policies and regulations and other contextual factors pose limitations to pursuing OBRSAs.

Based on our stakeholder interviewee responses, the literature, and policy- and regulatory-related developments previously mentioned, we identified priorities for modifying selected policies and regulations to improve the outlook for OBRSAs. Table 5 lists these and presents actions for reform, as well as recent noteworthy developments arising from or otherwise related to these actions. Stakeholder advocacy, informed communications, and careful agency deliberations contributed to the 2018 FDA guidance documents that should broaden opportunities for OBRSAs, including options for their design, data collection, and earlier implementation. Other advocacy has informed the OIG regarding the need to protect VBCs from proposed roll-backs of safe harbor protections under the AKS.

Improved conditions for OBRSAs depend on monitoring of and response to existing and proposed policies, regulations, and other factors. Proposed changes in price negotiation by government payers, price transparency, rebating practices, safe harbors, competitive bidding, alternative payment models, and pre- and postmarket information sharing for regulated products can greatly alter the risks and viability of OBRSAs.

Different stakeholder perspectives affect willingness to pursue OBRSAs and how they are negotiated. Given operational challenges of implementing OBRSAs and cost-of-care concerns that are broader than costs of individual drugs, health plans may consider OBRSAs as a lesser priority than manufacturers that seek OBRSAs as a means for securing a market foothold for newly approved therapies. Jointly addressing operational hurdles can align efforts to enable OBRSAs. This may entail shared responsibility or other collaborations to improve data infrastructure, collection, and standards to support OBRSAs; develop cross-company resources and relationships to pilot and support OBRSAs; and develop related management capacity and experience.

Information sharing about OBRSA models, pilot evaluations, and other experiences will strengthen the knowledge base, identify best practices, and support decisions regarding whether and how to conduct OBRSAs. Notwithstanding proprietary concerns about information sharing, the state of the art will continue to improve as experiences are conveyed via formal and informal channels. Large organizations-including the major PBMs and their partnerships with payers and providers-should expand the knowledge base and capacity for pursuing OBRSAs and other VBCs.

\section{Authors}

CLIFFORD GOODMAN, PhD, and CHRISTEL VILLARIVERA, MS, The Lewin Group, Falls Church, Virginia. KARL GREGOR, PharmD, MS, Optum, Fishers, Indiana, and JULIE VAN BAVEL, MPH, Merck Sharp \& Dohme, New South Wales, Australia.

AUTHOR CORRESPONDENCE: Christel Villarivera, MS, Managing Consultant, The Lewin Group, 3160 Fairview Park Dr. Ste. 600, Falls Church, VA 22042. Tel.: 703.269.5511;

E-mail: christel.villarivera@lewin.com. 


\section{DISCLOSURES}

This analysis was funded by Merck Sharp \& Dohme (MSD), a subsidiary of Merck, as a component of the Learning Laboratory for Advancing Value-Based Healthcare, which is a multiyear collaboration of MSD and Optum, a health services, technology, and data company. The manuscript underwent an internal review by the sponsor.

The Lewin Group (Lewin) is a subsidiary of OptumServe. OptumServe is wholly owned by UnitedHealth Group (UHG). Neither OptumServe nor UHG or its subsidiaries review the work products of Lewin. Lewin operates with editorial independence and provides its clients with health care and human services policy research and consulting services. Goodman and Villarivera are employees of Lewin; Gregor is an employee of Optum; and van Bavel is an employee of MSD. Goodman and Villarivera report fees from UHG, unrelated to this study

A poster presentation based on this manuscript was accepted and presented at the ISPOR Europe 2018 Conference in Barcelona, Spain, on November 13, 2018

\section{REFERENCES}

1. Centers for Medicare \& Medicaid Services. National health expenditures historical and projections 1960-2027. April 10, 2019. Available at: https:// www.cms.gov/Research-Statistics-Data-and-Systems/Statistics-Trends-andReports/NationalHealthExpendData/NationalHealthAccountsProjected. html. Accessed August 15, 2019.

2. PhRMA. Value-based contracts: 2019. June 7, 2019. Available at: https:// www.phrma.org/-/media/Project/PhRMA/PhRMA-Org/PhRMA-Org/PDF/ PhRMA_ValueBasedContracts_Q2_2019.pdf. Accessed August 21, 2019.

3. PwC Health Research Institute. Launching into value: pharma's quest to align drug prices with outcomes. September 2017. Available at: https://www. pwc.com/us/en/health-industries/health-research-institute/publications/ assets/value-based-drug-pricing.pdf. Accessed August 15, 2019.

4. Brow M, Macher D, Hughes K. Health plan interest in outcomes-based contracts increasing [press release]. Avalere. July 12, 2018. Available at: https://avalere.com/press-releases/health-plan-interest-in-outcomes-basedcontracts-increasing. Accessed August 24, 2019.

5. Health Resources \& Services Administration. 340B Drug Pricing Program. August 2019. Available at: https://www.hrsa.gov/opa/index.html. Accessed August 15, 2019

6. Duhig AM, Saha S, Smith S, et al. The current status of outcomes-based contracting for manufacturers and payers: an AMCP membership survey. J Manag Care Spec Pharm. 2018;24(5):410-15. Available at: https://www.jmcp. org/doi/10.18553/jmcp.2017.16326.

7. Nazareth T, Ko JJ, Sasane R, et al. Outcomes-based contracting experience: research findings from U.S. and European stakeholders. J Manag Care Spec Pharm. 2017;23(10):1018-26. Available at: https://www.jmcp.org/ doi/10.18553/jmcp.2017.23.10.1018.

8. Yu JS, Chin L, Oh J, Farias J. Performance-based risk-sharing arrangements for pharmaceutical products in the United States: a systematic review. J Manag Care Spec Pharm. 2017;(10):1028-40. Available at: https://www.jmcp. org/doi/10.18553/jmcp.2017.23.10.1028.

9. PhRMA. Value-based contracts: 2009-Q2 2019. June 7, 2019. Available at: http://phrma-docs.phrma.org/files/dmfile/PhRMA_ValueBasedContracts_ Q2_2019.pdf. Accessed August 15, 2019.
10. Mahendraratnam N, Sorenson C, Richardson E, et al. Value-based arrangements may be more prevalent than assumed. Am J Manag Care. 2019;25(2):70-76

11. Kelly C. Value-based contracts getting more safe harbor attention from OIG. Pink Sheet. December 10, 2017. Available at: https://pink.pharmaintelligence.informa.com/PS122104/ValueBased-Contracts-Getting-More-SafeHarbor-Attention-From-OIG. Accessed August 15, 2019.

12. Demske GE. Re: OIG Advisory Opinion No. 17-03. OIG, Department of Health and Human Services. August 18, 2017. Available at: https://oig.hhs. gov/fraud/docs/advisoryopinions/2017/AdvOpn17-03.pdf. Accessed August 15, 2019.

13. Ropes \& Gray. OIG's expanded interpretation of warranty safe harbor portends well for value-based health care. September 5, 2017. Available at: https://www.ropesgray.com/en/newsroom/alerts/2017/09/OIGs-ExpandedInterpretation-of-Warranty-Safe-Harbor-Portends-Well-for-Value-BasedHealth-Care.aspx\#fn2. Accessed August 15, 2019.

14. Academy of Managed Care Pharmacy. RE: Solicitation of new safe harbors and special fraud alerts [OIG-127-N]. February 26, 2018. Available at: https://amcp.org/sites/default/files/2019-06/AMCP\%20Summary\%20 Fraud\%20and\%20Abuse\%20Removal\%20of\%20Safe\%20Harbor\%20 Protection\%20for\%20Rebates\%20\%20_0.pdf. Accessed August 15, 2019.

15. Fraud and abuse; removal of safe harbor protection for rebates involving prescription pharmaceuticals and creation of new safe harbor protection for certain point-of-sale reductions in price on prescription pharmaceuticals and certain pharmacy benefit manager service fees, proposed rule. Fed Regist. 2019;84(25):2340-63. To be codified at 42 CFR Part 1001.

16. Patient Affordability Value and Efficiency Act, Section II. Exclusion of Certain Value-Based Arrangements from Anti-Kickback and Physician SelfReferral Prohibition. 116th Cong, lst Sess (2019). Available at: https://www.cassidy.senate.gov/imo/media/doc/PAVE\%20Act.pdf. Accessed August 20, 2019.

17. U.S. Food and Drug Administration. Drug and device manufacturer communications with payors, formulary committees, and similar entities questions and answers guidance for industry and review staff. June 2018. Available at: https://www.fda.gov/downloads/drugs/guidancecomplianceregulatoryinformation/guidances/ucm537347.pdf. Accessed August 15, 2019.

18. U.S. Food and Drug Administration. Medical product communications that are consistent with the FDA-required labeling - questions and answers guidance for industry. June 2018. Available at: https://www.fda.gov/ downloads/drugs/guidancecomplianceregulatoryinformation/guidances/ ucm537130.pdf. Accessed August 15, 2019.

19. Mattina C. Trust is the key ingredient in Medicaid value-based contracts, manufacturers and payers agree. AJMC. March 26, 2019. Available at: https://www.ajmc.com/conferences/amcp-2019/trust-is-the-key-ingredient-in-medicaid-valuebased-contracts-manufacturers-and-payers-agree. Accessed August 15, 2019.

20. Dworkowitz A, Fiori A, Bachrach D. Extending VBP models into Medicaid drug purchasing: challenges and opportunities. Health Affairs Blog. May 22, 2019. Available at: https://www.healthaffairs.org/do/10.1377/ hblog20190520.247063/full/. Accessed August 15, 2019.

21. Prime Therapeutics. Prime Therapeutics and Boehringer Ingelheim enter into outcomes-based contract for Jardiance [press release]. January 29, 2018. Available at: https://www.primetherapeutics.com/en/news/pressreleases/2018/ jardiance-carecenterecontract-release.html. Accessed August 18, 2019. 